\title{
Introdução às Origens da Improdutividade no Brasil
}

Ivan Guerra Machado ${ }^{1}$

1 Universidade Federal do Rio Grande do Sul - UFRGS, Programa de Pós-graduação em Engenharia de Minas, Metalúrgica e de Materiais - PPGE3M, Laboratório de Soldagem \& Técnicas Conexas, Porto Alegre, RS, Brasil.

Recebido: 23 Nov., 2017

Aceito: 23 Nov., 2017

E-mail: welder@ufrgs.br (IGM)
Este é um artigo publicado em acesso aberto (0pen Access) sob a licença Creative Commons Attribution Non-Commercial, que permite uso, distribuição e reprodução em qualquer meio, sem restriç̄es desde que sem fins comerciais e que 0 trabalho original seja corretamente citado.
Resumo: Principalmente para países em desenvolvimento, não deveríamos analisar a tríade produtividade, competitividade e inovação somente considerando aspectos econômicos e/ou administrativos. É de suma importância incluir na investigação fatores específicos de cada país, tais como sequelas devido à forma que ocorreu a colonização, agressões contra o ambiente, posição geográfica, além de questões de ordem política e institucional, pois muitos deles ainda não alcançaram harmonia nestes quesitos.

Palavras-chave: Produtividade industrial; Improdutividade; Competitividade; Inovação; Fatores sociais e culturais.

\section{Introduction to the Origins of Unproductivity in Brazil}

\begin{abstract}
Particularly for developing countries, we should not analyse the triad productivity, competitiveness and innovation only considering economics and/or administrative aspects. It is of paramount importance to include in the investigation specific factors of each country, such as sequels due to the way colonization occurred, aggressions against the environment, geographic position, besides questions of political and institutional order, for many of them have not yet achieved harmony in these issues.
\end{abstract}

Key-words: Industrial productivity; Unproductivity; Competitiveness; Innovation; Social and cultural factors.

\section{Introdução}

É nossa intenção neste artigo evidenciar para engenheiros e técnicos atuantes em tecnologia da soldagem, que são de pouca valia esforços isolados para a redução dos custos totais, se concomitantemente não ocorrer, com extrema eficiência, a transformação dos recursos disponíveis em produtos (físicos ou não), sendo esta, aliás, a mais simples e geral definição de "produtividade". Além disto, se quisermos sobreviver como nação soberana e povo dono do seu destino, teremos que manter elevados os níveis de competitividade e inovação em qualquer empreendimento, seja qual for a sua origem, e esquecer os tempos que nós (brasileiros) invariavelmente apontávamos (muitas vezes) nebulosos "fatores externos" como origens de todas as nossas mazelas e fracassos.

Não examinaremos ao longo deste trabalho detalhes técnicos relativos à produtividade, mas enfatizaremos ad nauseam a importância deste vital assunto para todas as nações e "firmas" - conceituadas [1] como organizações que produzem e vendem bens e serviços, que contratam e utilizam fatores de produção, reunindo capital e trabalho e agregam valor às matérias-primas através do emprego de tecnologia. Para tanto, entendemos que não há nada melhor do que iniciarmos apresentando este trecho do livro do (prêmio Nobel) Paul Krugman [2] (p. 11), que transcrevemos ipsis litteris:

Produtividade não é tudo, mas no longo prazo é quase tudo. A habilidade de um país em melhorar seu padrão de vida com o passar do tempo depende quase que inteiramente da sua habilidade de elevar sua produção por trabalhador.

Produtividade é um território geralmente dominado por economistas, que infelizmente raramente abordam aspectos das falhas de todos os tipos que ocorrem nas indústrias, conforme veremos na seção 3 deste artigo, através de uma singela e franca declaração sobre este assunto de um reconhecidamente competente $\mathrm{PhD}$ em economia. Então, é mister mencionarmos, que decidimos abordar esta questão, somente após termos sido questionados várias vezes e em diferentes situações por (principalmente) pessoas ligadas à indústria da soldagem, sobre o porquê de não conseguirem reduzir significativamente 
os custos totais de produção, apesar de ou terem adquirido equipamentos de última geração, similares a de países plenamente desenvolvidos, ou terem "treinado" muito bem seus colaboradores.

Notamos, então, que muitos deles percebiam o conceito de forma errada, ou parcialmente errada, pois produtividade trata de trabalhar mais inteligentemente, não trabalhar mais arduamente, e reflete nossa habilidade de produzir mais através de melhor combinação dos recursos, devido a novas ideias, inovações tecnológicas e modelos de negócios [3].

A cada questionamento deste tipo, sentíamo-nos novamente sentados num anfiteatro há mais de 30 anos e após lendo o livro do palestrante, o excelente Waldimir Pirró e Longo [4] (p. 10), do qual retiramos este pequeno e simples, mas decisivo excerto:

[...] chega-se ao absurdo de acreditar que, quando uma empresa coloca em funcionamento aqui o último modelo de uma máquina importada de fazer pregos, o país está dotado da mais alta tecnologia de fazer pregos.

Depois de tantos anos acreditávamos estar esta questão absolutamente pacificada no Brasil, mas vemos que infelizmente isto não é verdade, pois alguns ainda confundem [4] o domínio do conjunto de conhecimentos específicos com as instruções que ele gera para a produção de bens ou serviços.

Além disso, as contribuições para a produtividade geralmente mencionadas pela maioria das pessoas são aquelas exclusivamente devido ao trabalho e ao capital, esta última incluindo máquinas e equipamentos. Porém, há diversas formas de se calcular a produtividade e é preciso diferenciar a produtividade do trabalho, que dá a medida da eficiência deste item, da produtividade total dos fatores de produção, que inclui, além do trabalho, os bens de capital (máquinas e equipamentos). Então, quando ocorre um aumento de produção, podemos diferenciar se o os ganhos foram devido a eficiência ou, por exemplo, consequência da compra de um equipamento. Em geral, calculamos a produtividade do trabalho dividindo o PIB (Produto Interno Bruto) pela quantidade de pessoas ocupadas ou o total de horas trabalhadas (o que contabiliza os efeitos das horas extras). Já na produtividade total dos fatores de produção dividimos o PIB pelo resultado de uma função matemática que pondera o estoque de capital e a quantidade de trabalho. Lembremos que o PIB representa a soma de todos os produtos finais produzidos por um país em um intervalo de tempo e nessa conta entram todos os bens e serviços consumidos pelas pessoas, empresas e governo.

Porém, existe uma terceira vertente, que não pode ser explicada pela taxa de alteração destas duas e é usualmente interpretada como a contribuição para o crescimento econômico de fatores devidos principalmente a inovações técnicas e organizacionais. Esta contribuição reflete a eficiência com que são usados os recursos, envolvendo a melhoria no gerenciamento dos processos de produção, alteração organizacional ou de pesquisa e desenvolvimento (P\&D) e inovação. Por medir o crescimento residual, que não encontra explicação na taxa de alteração do trabalho e capital, alguns autores que escreveram clássicos sobre o tema (citados em 3) apontam estes fatores como sendo uma medida da nossa ignorância.

Por sua vez, também tentaremos mostrar que razões históricas, culturais, geográficas, políticas e ambientais tornam os fatores com preponderante influência sobre a produtividade no nosso país, muito mais complexos do que usualmente mencionados na literatura especializada. Finalmente para nós está claro, que investimentos unicamente em recursos humanos e máquinas - aliás, ambos deixando muito a desejar há muitas décadas no Brasil - apesar de fundamentais não provocarão notáveis aumentos de produtividade no curto prazo da nação e das suas firmas, caso sejam desconsiderados seriamente os efeitos que o tipo de sociedade que herdamos e que mantemos exerce sobre este assunto.

\section{Princípios e Alguns Fatos}

Por que as sociedades europeias após o século XV foram as conquistadoras? Cresce a relevância desta nossa pergunta, quando sabemos que pelo menos nos 6000 anos anteriores as sociedades do Crescente Fértil, da China ou mesmo da Índia eram as líderes indiscutíveis e até cerca do ano 1450 o fluxo de ciência e tecnologia partia das sociedades islâmicas ao norte da África, sendo a China o grande expoente em tecnologia. Por sua vez, na África surgiram os humanos modernos; por que as armas e o aço não apareceram primeiro lá, permitindo que seus povos e germes [5] conquistassem a Europa? Se visitantes de outro planeta estivessem na Terra há cerca de 11.000 anos, 
provavelmente apostariam que os africanos a dominariam. Também, por que 168 esfarrapados soldados espanhóis liderados por Pizzarro capturaram em pouco tempo o monarca inca Ataualpa, que estava cercado por entorno de 80.000 guerreiros? Poderia parte da explicação de Ataualpa não ter ido a Madri capturar o rei Carlos I incluir germes espanhóis, cavalos, cultura, organização política e tecnologia (especialmente navios e armas)? Por que a escrita se difundiu do Crescente Fértil para a Etiópia e Arábia, mas não do México para os Andes?

Há indiscutíveis fatos sobre as questões do efeito da geografia (e ambiente) sobre o desenvolvimento das sociedades, apresentados magistralmente por Diamond [5]; ele nos diz que nas terras na mesma latitude (leste-oeste e vice-versa) é muito mais rápida a difusão de culturas, animais domesticados, produtos agrícolas, germes etc., do que nas terras de mesma longitude (norte-sul e vice-versa). Por exemplo, uma infinidade de culturas de grãos, escrita, tecnologias etc. foram difundidas entre sociedades do Crescente Fértil até a China (e vice-versa), enquanto muito pouco se difundiu do norte para o sul (e vice-versa) das Américas e na sua maior parte isso se deve as grandes diferenças climáticas e a existências de barreiras geográficas naturais.

Esse mesmo autor demonstrou que a diversidade humana é o resultado de processo histórico e determinados rumos são seguidos por diferentes povos, devido principalmente às diferenças entre ambientes e não às diferenças biológicas, tendo teorias racistas sido esmagadas por fatos que as contradizem. Com relação às razões das diferenças no nível de evolução dos povos nos primórdios da humanidade, existem muitas perguntas, mas ainda poucas respostas. O fato é que "nos 13 mil anos que se passaram desde o fim da última Era Glacial, algumas partes do mundo desenvolveram sociedades industriais e letradas, que usavam utensílios de metal, enquanto outras produziram apenas sociedades agrícolas analfabetas e ainda outras se mantiveram caçadoras-coletoras de alimentos, usando artefatos feitos com pedras". Isso é de extrema importância, pois numa visão pragmática da evolução humana e mesmo que seja chocante [5] "[...] as sociedades letradas que possuíam utensílios de metal conquistaram ou exterminaram as outras sociedades". Além disto, lembremos que, em geral, os perdedores nunca tiveram qualquer direito, ou seja, "Vae victis!" ("Ai dos vencidos!").

Diversas teorias podem parcialmente explicar o porquê da baixa produtividade dos trabalhadores da América Latina em geral e do Brasil em particular. Certamente a maneira como esta parte do mundo foi conquistada e colonizada causou grande e negativo impacto sobre os métodos de produção e as populações, pelo menos nos primeiros 300 anos da sua história. Conforme um estudo de impressionante fôlego, Maddison [6] nos mostra que as Américas no tempo das conquistas espanholas eram pouco povoadas. A população era um terço daquela da Europa Ocidental e a área do território onze vezes maior. O nível tecnológico era muito inferior. Não existiam veículos com rodas ou animais de tração, ferramentas, armas ou arados de metal, nem gado, ovelha, porco ou galinhas. As áreas mais densamente habitadas (México e Peru) tinham significativos centros urbanos e agricultura vegetariana sofisticada.

As populações americanas não tinham resistência [6] às doenças europeias (varíola, sarampo, gripe e tifo) nem às africanas (febre amarela e malária) e aproximadamente na metade do século XVI dois terços delas foram aniquiladas, sendo a mortalidade o dobro daquela da Europa durante a "peste negra" do século XIV. As duas civilizações avançadas (Asteca no México e Inca no Peru) foram destruídas. Suas populações foram reduzidas a anomia e servidão. Populações de caçadores-coletores em outras partes foram marginalizadas ou exterminadas. A economia destas terras relativamente vazias foi completamente alterada. A parte Latina do continente foi repovoada pelo envio de 7,5 milhão de escravos africanos e chegada de 1,5 milhão de colonos europeus, que tinham mais alta fertilidade, mais longa expectativa de vida e muito mais altos rendimentos médios do que os escravos e a população indígena.

Ainda que o impacto inicial da conquista tenha sido massivamente destrutivo, o potencial econômico de longo termo foi grandemente elevado [6]. A capacidade de suportar uma população maior foi aumentada pela introdução de novos cultivos e animais. Entre muitos outros, os novos itens foram trigo, arroz, cana de açúcar, videiras, café, etc. e animais para alimentação tal como gado, porcos, galinhas, ovelhas e cabras. A introdução de animais para transporte e tração - cavalos, asnos e mulas - juntamente veículos com rodas e arados (os quais substituíram varas de escavação) foram uma importante contribuição para a capacidade produtiva. Ocorreu uma transferência recíproca de cultivos do Novo Mundo para a Europa, Ásia e África - entre eles, milho, batatas, mandioca, pimentas, tomates, etc. - os quais elevaram a capacidade de produção e a habilidade do resto do mundo para sustentar o crescimento da população. 
Ainda segundo Maddison [6], a experiência das Américas entre 1500 e 1820 foi muito diferente dos outros continentes. A catástrofe demográfica do século dezesseis e o colapso da economia indígena não tem paralelo em nenhum outro lugar. A população e a produção se recuperaram um pouco no século XVII, mas ainda bem abaixo dos níveis de 1500. O crescimento se acelerou no século XVIII. Entorno de 1820 o PIB era o dobro daquele de 1500, e a média dos ganhos per capita acima da média mundial. A economia, a tecnologia e as instituições econômicas tinham sido transformadas. A maior parte do continente se encontrava num processo de obter independência política. De 1820 até 2001, a expansão demográfica foi o aspecto mais dinâmico do desenvolvimento da América Latina, com a população crescendo 24 vezes, comparada com 3 vezes nas antigas metrópoles (Espanha e Portugal). Porém, o comportamento do PIB per capita foi menos impressionante, pois aumentou 8 vezes, enquanto nas antigas metrópoles o aumento foi de 15 vezes e na América do Norte foi de 22 vezes.

Sabemos [7] que até cerca de 1820 as taxas de crescimento mundial da população e da produção por habitante do planeta cresciam lentamente, quando então ocorreu uma clara e elevada aceleração. Sem coincidência alguma esta é aproximadamente a mesma época que começaram os primeiros grandes desenvolvimentos e invenções com cunho tecnológico, resultando na denominada "Revolução Industrial", cujo epicentro foi a Grã-Bretanha. Porém, notemos que após o recorde histórico de 1,9\% da taxa de crescimento da população entre 1950 e 1970, a previsão é de que entorno de 2070 ocorrerá um retorno ao extremamente baixo crescimento demográfico pré-1700, ou até mesmo negativo. Por outro lado, a taxa de crescimento da produção por habitante superou $2 \%$ entre 1950-2012, quase um século após o pico demográfico e é previsto que ultrapasse $2,5 \%$ até 2050 , sofrendo grande redução após esse período.

Por sua vez, ilustramos melhor ainda esta questão apresentando nas Figuras $1 \mathrm{a}$, b a distribuição da população e PIB mundial, respectivamente, desde o ano 1000 [adaptado de 7]. Na Figura 1a está a distribuição da população mundial nos quatro continentes, não considerando a Oceania, (éramos 7,052 bilhão em 2012). Observemos que a proporção de habitantes na Ásia sempre foi superior a 50\%, seguido pela Europa que teve um pico no início do

(a)

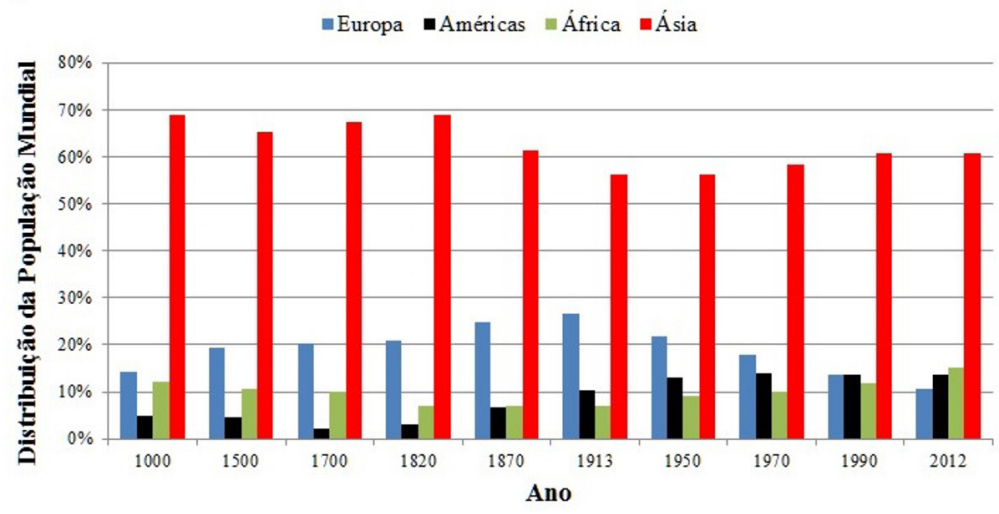

(b)

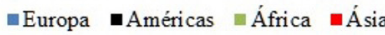

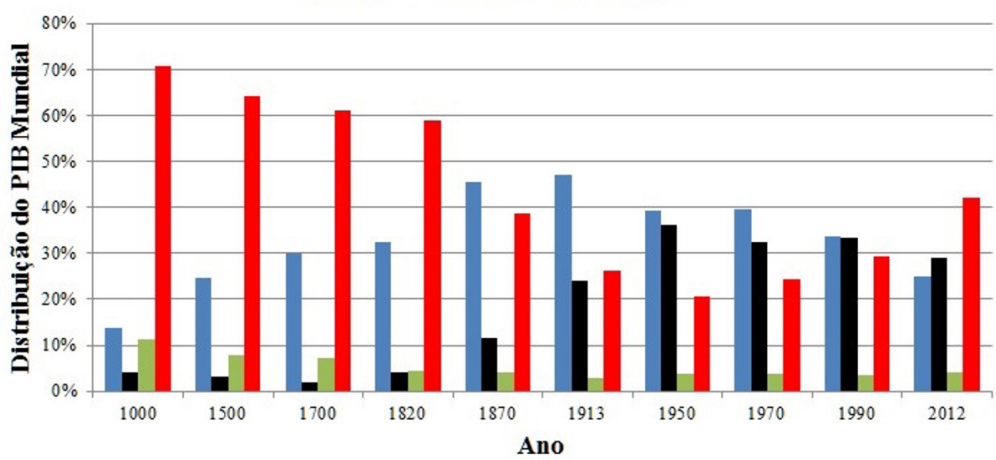

Figura 1. Distribuições nos continentes da população mundial (a) e do PIB mundial (b) desde a Antiguidade até a atualidade [adaptado de 7]. 
século XX e que foi ultrapassado pelas Américas entorno de 1990. Um fato novo é a aceleração do crescimento demográfico da África. Por sua vez, na Figura 1b está a participação de cada continente no PIB. Em 2012 o PIB mundial era de 71.170 bilhão de euros PPC, onde PPC é a "paridade do poder de compra". Vemos que a participação no PIB da África praticamente não se alterou. Enquanto isto, a Ásia foi líder absoluto na participação do PIB mundial por mais de dez séculos, mas sofreu forte queda entre 1820 e 1970 - por razões históricas facilmente identificáveis. Este continente novamente ultrapassou os outros entorno de 2010 e as Américas ficaram à frente da Europa em cerca de 1990. Além disto, observamos que as máximas taxas de crescimento do PIB mundial ocorrem quando as Américas e a Europa estão à frente.

Além das tragédias e misérias que impuseram principalmente aos povos indígenas e africanos, adicionalmente existem outras questões erradas com as sociedades ditas "vencedoras" e que, sem dúvida, devem e podem ser corrigidas. Por exemplo, reconhecendo que os problemas ambientais não são interrompidos nas fronteiras entre os países, em 1977 o presidente dos EUA Jimmy Carter, determinou que fosse desenvolvido um estudo com a finalidade de "[...] descobrir as implicações de longo prazo das tendências atuais do mundo em população, recursos naturais, e o ambiente até o final do século" e, assim, "[...] estabelecer os fundamentos do planejamento de longo alcance do Governo". Três anos após, um dos mais amplos estudos até então empreendidos foi publicado [8] e, sob o aspecto qualitativo, infelizmente as suas principais conclusões foram certeiras e mantém validade até hoje, ou seja:

Se as tendências atuais continuarem, o mundo em 2000 será mais populoso, mais poluído, menos estável ecologicamente, e mais vulnerável a disrupção do que o mundo que nós vivemos agora. Sérias tensões envolvendo população, recursos e ambiente estão claramente visíveis à frente. Apesar da maior produção material, as pessoas do mundo serão mais pobres em muitas maneiras do que são hoje. Para centenas de milhões dos desesperadamente pobres, a perspectiva para comida e outras necessidade da vida não serão melhores. Para muitos, ela será pior. Salvo avanços revolucionários em tecnologia, a vida para a maioria das pessoas sobre a Terra será mais precária em 2000 do que ela é agora - a não ser que as nações do mundo ajam decisivamente para alterar as tendências atuais.

Por outro lado, importantes aspectos complementam os efeitos que descrevemos. Aqui exemplificaremos com questões envolvendo a China medieval, de onde provieram muitos e importantes inventos "tecnológicos", tais como o ferro fundido, a bússola, a pólvora, o papel e a imprensa, etc., além dela ter se sobressaído em questões políticas, navegação e domínio dos mares, como mencionamos há quase vinte anos num pequeno artigo [9] baseados em um interessantíssimo livro [10]. Muito tempo antes das navegações dos espanhóis e portugueses, os chineses mantinham relações comerciais com o mundo islâmico, conheciam o sul do Mediterrâneo e tinham cartografado o rio Nilo, a costa oriental da África e a Índia. Porém, as suas mais espetaculares expedições navais ocorreram entre 1405 e 1433, comandadas por Cheng Ho nomeado pelo imperador Yongle. A frota era geralmente composta por uma tripulação de aproximadamente 37.000 homens e cerca de 370 (extraordinariamente bem construídos) navios de vários andares, com o maior deles, "O Barco do Tesouro", medindo $133 \mathrm{~m}$ de comprimento, com 54 m de largura máxima e 9 mastros (!), provavelmente a maior nau a singrar os mares até então. Em cada porto que atracava esta imensa frota, Cheng Ho transmitia ao líder local mensagens de amizade do seu imperador e ofertava-lhe presentes muito valiosos - da mesma forma como agiram seus antecessores nos últimos 500 anos. Não era propósito de Cheng Ho a exploração material de espécie alguma, nem impor qualquer tipo de crença religiosa - a China deveria mostrar ao mundo que tudo possuía. Muito pelo contrário, ele incentivava as religiões locais e protegia a população dos ataques de piratas que existiam naqueles mares. Em troca, recebia tributos geralmente de menor valor do que os presentes dados, mas com especial significado, pois estabelecia relações diplomáticas e obtinha o respeito dos povos que visitava, além do reconhecimento de que a China era o único centro de civilização (este era o principal objetivo das expedições). Porém, é instigante a questão, do porque os barcos chineses não terem seguido para o oeste, contornando o cabo ao sul da África e se dirigido para colonizar a Europa, antes de Vasco da Gama e suas minúsculas naus ter contornado o Cabo da Boa Esperança para o leste e iniciado a colonização da Ásia oriental. Ou por que os chineses não cruzaram o Pacífico e colonizaram a costa ocidental das Américas?

Mais estarrecedor, ainda, é o fato de que pouco antes de 1500 e quase subitamente, as frotas chinesas foram paralisadas e em seguida desmanteladas. A razão mais plausível parece ter sido uma luta pelo poder na corte entre os eunucos e seus adversários. Como eram os eunucos responsáveis pelo envio destas grandiosas frotas e como os seus adversários venceram a disputa; como vingança os estaleiros foram destruídos e na China não 
mais poderiam trafegar embarcações transoceânicas! Então, o Império chinês sofreu um processo de constante decadência, provavelmente devido a sua política isolacionista e de dar mais do que receber, a fim de satisfazer o imenso ego dos seus imperadores, terminando por ser, literalmente, saqueado por várias potências ocidentais durante o século $X X$.

Então, além dos efeitos sobre as sociedades da geografia, de fatores históricos devido à colonização e das agressões que (principalmente) as sociedades "vencedoras" cometem contra o ambiente, uma nação poderá realmente prosperar apenas quando os seguintes fatores, descritos detalhadamente em Bernstein [11], estiverem concomitantemente disponíveis:

1. Direitos de propriedade: Inovadores e comerciantes precisam garantias de que os frutos de seu trabalho não sejam arbitrariamente confiscados pelo Estado, por criminosos ou por monopolistas. As pessoas devem ter garantias de que manterão a maior parte da justa recompensa pelas suas propriedades, inclusive a intelectual. Notemos que o direito de propriedade jamais é absoluto. Mesmo os governos mais libertários em termos econômicos impõem certos tributos;

2. Racionalismo científico: O progresso econômico depende não somente do desenvolvimento de ideias, mas também da sua comercialização. Deve haver sustentação para o processo inventivo e é imprescindível dispor de uma infraestrutura de pensamento racional, baseado em observações empíricas e ferramentas matemáticas para sustentar o avanço tecnológico. Observemos que o método científico tem sido utilizado pelo menos nos últimos 400 anos no ocidente;

3. Existência de mercados de capital: Para financiar novos bens e serviços, é necessário dinheiro disponível para investimento. Geralmente os empreendedores não dispõem dos recursos pecuniários necessários;

4. Transporte e comunicações rápidos e eficientes: De nada adianta os empreendedores terem seus direitos de propriedade garantidos, as ferramentas intelectuais necessárias e o capital adequado se não conseguem divulgar os seus produtos (bens e/ou serviços) e entregá-los com rapidez e baixo custo.

Além disso, temos que reconhecer não ser possível um país manter a base da sua economia sobre a comercialização quase que exclusivamente de "commodities", mesmo que possua vantagens comparativas, pois em geral os seus preços variam conforme interesses outros, que não necessariamente aqueles dos produtores, conforme mostramos [12] na Figura 2. Convenhamos que não é sustentável no longo prazo uma sociedade esperar ser mantida por um tipo de renda, cujo comportamento tem largo grau de incerteza e em grande parte é independente dos seus planejamentos estratégicos.

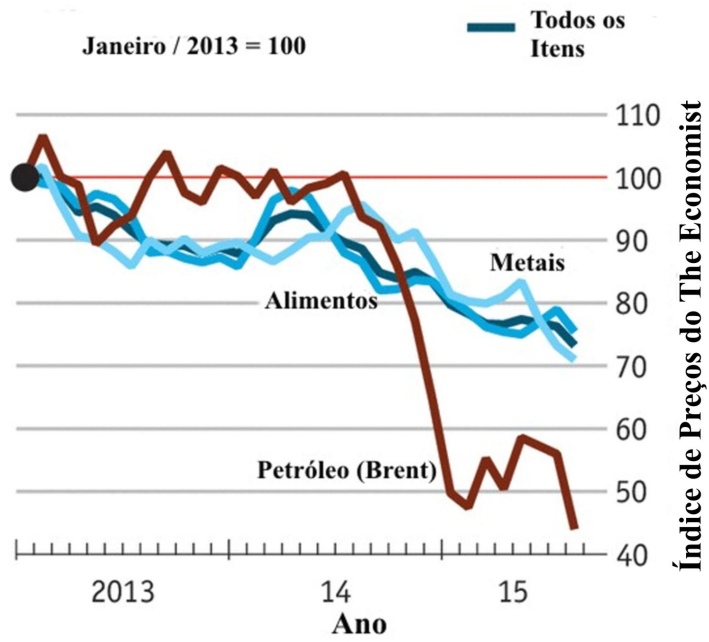

Figura 2. Variações dos preços das "commodities" e alimentos nos últimos anos [12]. "Todos os Itens" baseado no índice de preços do The Economist. 
Por outro lado, na Figura 3 ilustramos a variação do custo do trabalho na manufatura e do PIB por trabalhador, entre os anos de 2005 e 2015 para diferentes países em diversos níveis de desenvolvimento [13]. Imediatamente nos chama a atenção os elevados custos do trabalho e participação no PIB por trabalhador na Alemanha, EUA e Japão. Também é digno de nota, que na China neste intervalo de 10 anos aumentou 371\% o custo do trabalho e $137 \%$ o PIB por trabalhador. Portanto, somente salário reduzido de há muito deixou de ser fator decisivo para atração de capital internacional.

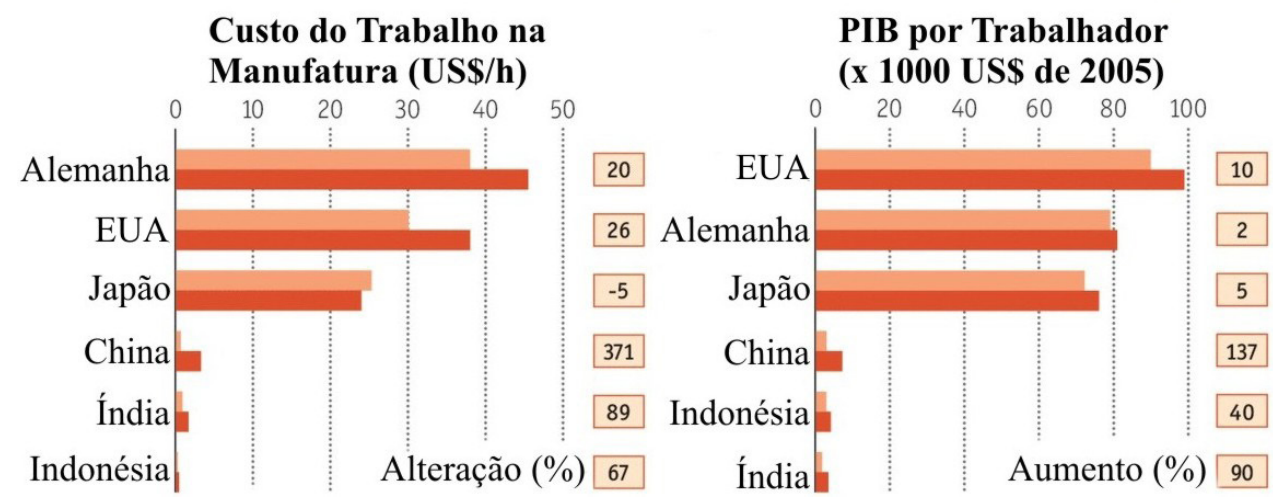

Figura 3. Comparações entre 2005 e 2015 do custo do trabalho na manufatura e do PIB por trabalhador, com as respectivas variações porcentuais [13].

Nesta nossa apresentação de alguns fatos objetivos pretendemos mostrar aos leitores a importância de sermos realistas ao enfrentarmos as questões globais. Portanto, é ilustrativo observarmos na Figura 4 como varia em diferentes períodos de tempo um conceito muito importante, que é o denominado "Poder Econômico Global" dos países [14], sendo estimado pela participação (em porcentagem) de um país no PIB do mundo, no comércio e na exportação líquida de capital. É evidente a queda radical da dominação britânica (GB) desde 1870 e a rápida ascensão dos EUA, com a provável alteração do quadro num futuro próximo incluindo novos atores a partir de 2020, principalmente a China e a Índia, com o Brasil (mais uma vez) não se destacando nesta questão.

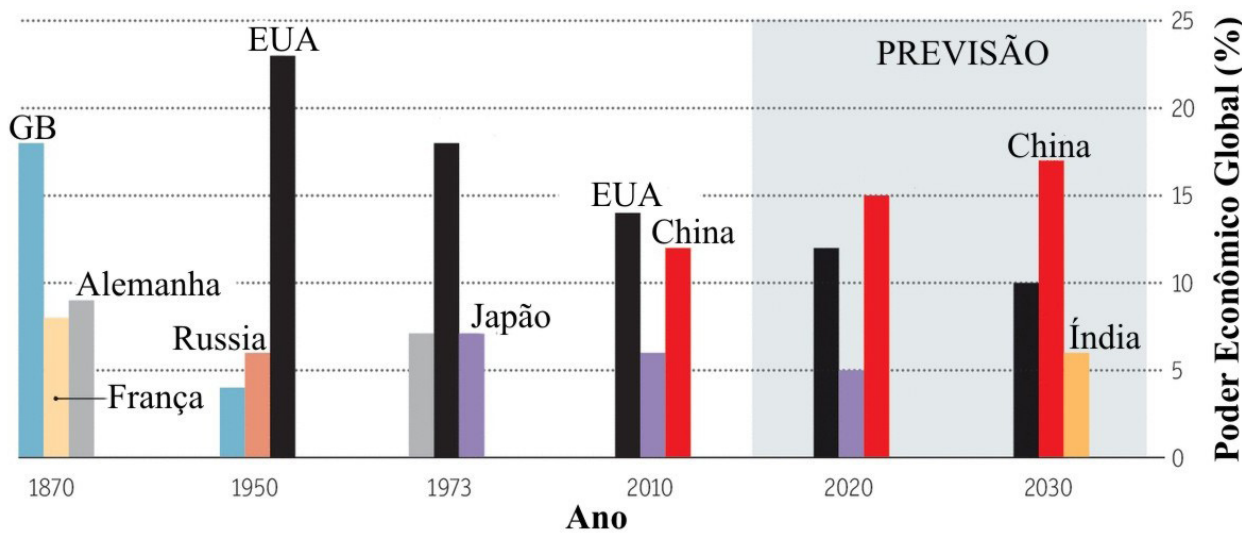

Figura 4. Poder Econômico Global dos países em diferentes épocas [14].

\section{Tríade Produtividade, Competitividade e Inovação}

Aprendemos que elevar a produtividade deveria ser objetivo incessantemente perseguido por qualquer organização privada, ou estatal, e política prioritária de qualquer nação. Porém, geralmente não é isto que vemos nos países da América Latina, por exemplo, nos quais em média um trabalhador produz um quinto daquele dos EUA, existindo grandes lacunas tanto de capital, quanto de eficiência [15]. Claramente este fato também se reflete 
em enormes diferenças salariais entre esses grupos e apesar da "boa vontade" em resolver estas questões expressa pelos atores envolvidos com poder decisório, muitas vezes não fica claro quais componentes são os mais destacados.

No Brasil, em particular, algumas falhas são evidentes e como mencionamos na Introdução, o PhD em Economia Cláudio Castro [16] escreveu o seguinte, em artigo que seria hilário, não fosse trágico:

[...] os que escrevem sobre produtividade no Brasil tendem a ser economistas. Portanto, falam de taxa de câmbio, alíquotas, custo da informação e muitos outros de seus inventos (falo com impunidade, pois sou um deles). Do mundo real, nem um pio (uma newsletter recente reproduz 12 artigos sobre produtividade, nenhum fala do processo de trabalho).

E mais adiante ele complementa: "O desperdício de material de construção é pavoroso - estima-se em 30\%".

Na Figura 5 comparamos a produtividade do trabalhador brasileiro com aqueles de outros países [17]. Observamos que somente os trabalhadores da China e da Índia são menos produtivos que os brasileiros (a produtividade relativa ultrapassa 100\%), mas mesmo assim é óbvio que nestes últimos 15 anos eles melhoraram muito. Por outro lado, é gritante a nossa menor produtividade em relação aos americanos: em 1950 um trabalhador brasileiro produzia tanto quanto 24,3\% do americano; aumentou para 38,9\% em 1980 e despencou para 24,1\% em 2015.

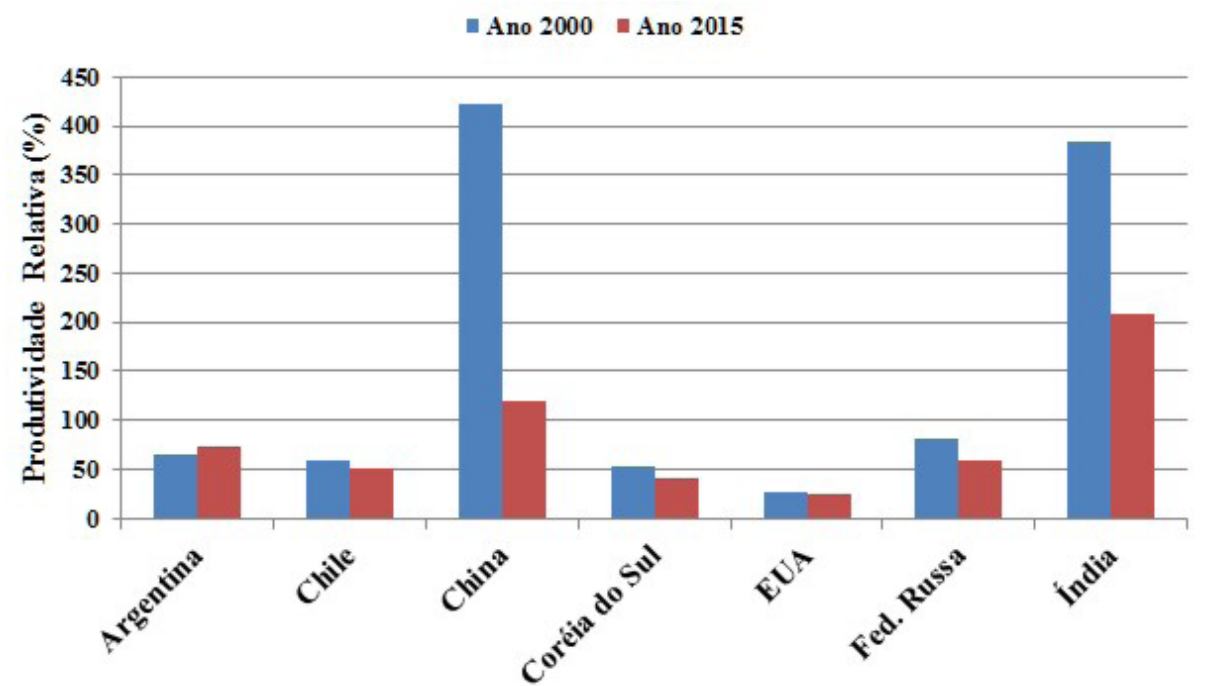

Figura 5. Produtividade dos trabalhadores de diversos países em relação ao trabalhador brasileiro, nos anos 2000 e 2015 [17].

Será que esta enorme desigualdade de produtividade se deve somente à falta de habilidade, desconhecimento, ou mesmo ausência de vontade de "fazer bem feito" do trabalhador brasileiro? Entendemos que existem causas muito mais profundas e complicadas e exemplificamos com dados da Oxfam Brasil [18]: (a) seis pessoas detêm a mesma riqueza dos 100 milhões de brasileiros mais pobres; (b) aproximadamente 99\% dos brasileiros precisam dividir essa conta com o 1\% restante; (c) se mantidas as tendências dos últimos 20 anos, mulheres só terão seus salários equiparados aos dos homens em 2047 e negros terão isonomia salarial em relação aos brancos apenas em 2089; (d) os 5\% que estão no topo da pirâmide econômica do Brasil concentram a mesma renda dos 95\% restantes; (e) um trabalhador que receba um salário mínimo mensal levará 19 anos para ganhar o mesmo que aqueles que integram o 0,1\% mais rico do país recebem em apenas um mês; (f) os $10 \%$ mais pobres do país gastam 32\% de sua renda em tributos, a maior parte deles indiretos (sobre bens e serviços), enquanto os $10 \%$ mais ricos gastam $21 \%$.

Para reforçarmos estas assertivas, mostramos [19] na Figura 6 a participação na renda nacional de diversos segmentos da população com poderes aquisitivos muito diferentes. Observemos que - apesar de afirmações contrárias feitas por pessoas ou instituições mal informadas, ou inescrupulosas - as proporções se mantiveram praticamente estáveis entre os anos 2001 e 2015, com os 10\% mais ricos possuindo mais da metade da renda brasileira. 


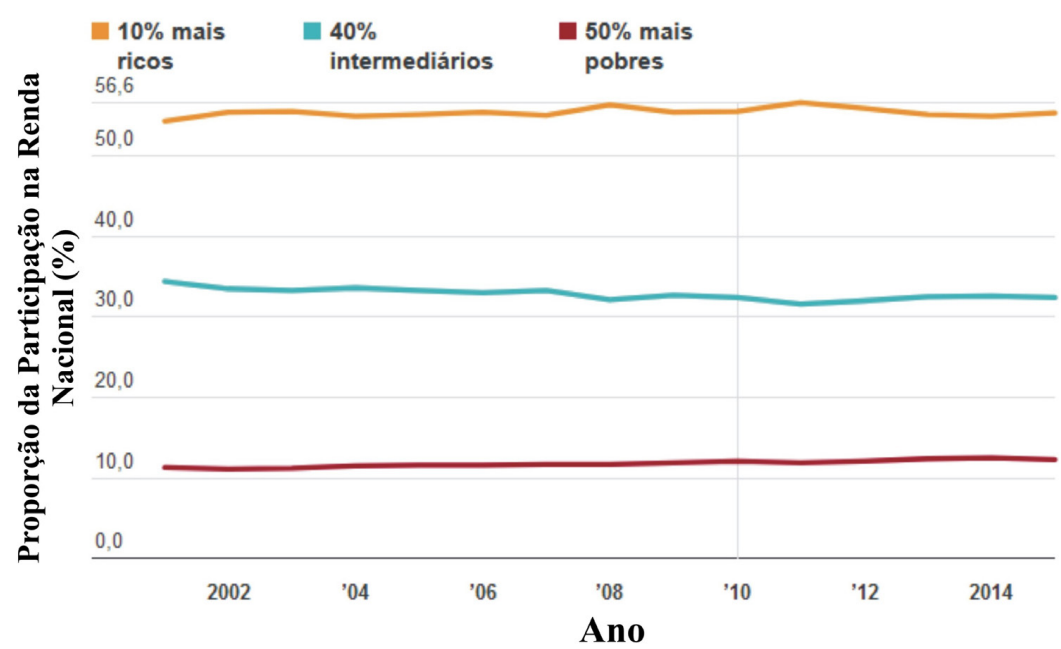

Figuras 6. Participação na renda nacional em diferentes anos, de setores da sociedade com diferentes poderes aquisitivos [19].

Por sua vez, na Figura 7 apresentamos a participação destes $10 \%$ mais ricos, mas agora comparando o Brasil com os EUA, a França e a China [19]; é simplesmente brutal a diferença na distribuição. No Brasil a média de renda anual foi cerca de US\$ 541 mil entre os $1 \%$ mais ricos da população (aproximadamente 1,4 milhão de pessoas) em 2015 - superior à renda média do equivalente 1\% francês (US\$ 450 mil a US\$ 500 mil). Ao mesmo tempo, a renda média dos $90 \%$ mais pobres no Brasil equivale à média dos $20 \%$ mais pobres da França. Os mais ricos no Brasil têm, então, uma renda superior aos mais ricos da França, enquanto a maioria dos brasileiros tem renda equivalente aos franceses mais pobres. Além disto, os lucros não distribuídos de empresas fechadas, que cresceram a uma taxa três vezes superior à remuneração de empregados entre 2000 e 2015 (231\% versus 74\%), mostram que embora tenha ocorrido uma melhora na igualdade salarial, os recursos concentrados entre a população mais rica expandiram-se a uma taxa muito maior.

Apesar disto, as fontes exatas dessas diferenças precisam ser investigadas e aqui citamos literalmente Francesco Caselli [15] (p. 1):

Se lacunas devido a capital físico e humano (lacunas de capital) são suficientes para explicar a maioria das diferenças de renda, então as soluções devem ser procuradas através de investimentos em máquinas e em humanos. Porém, se as diferenças em capital são insuficientes para explicar a maioria das variações de renda, deve ser concluído que os países em desenvolvimento também fazem uso ineficiente dos seus

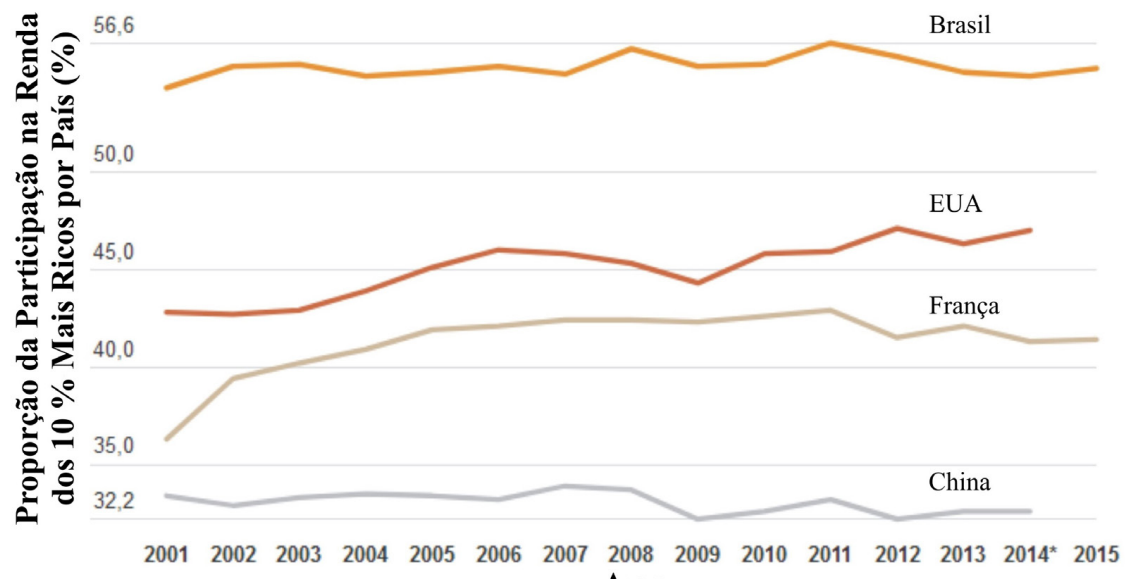

Ano

Figura 7. Participação dos $10 \%$ mais ricos na renda de cada país [19]. 
recursos, ou seja, apresentam lacunas de eficiência. Então, neste caso a agenda da pesquisa e da política deve ser focada sobre tecnologia, alocação de eficiência, inclusive do capital, competição, etc.

Concordamos com alguns depoimentos prestados [20] por autoridades no assunto, tal como Célio Hiratuka, da Unicamp: “Em termos de cultura gerencial, o Brasil não é tão diferente de outros países que têm produtividade mais elevada". Complementamos com a opinião de que a questão relaciona-se ao pequeno avanço em termos culturais da engenharia nacional. Sem dúvida ocorreu uma "revolução" nas áreas administrativas das firmas, mas não aconteceu o mesmo com a engenharia (projeto, produção, etc...). Além disto, análises constatam [20] que os seguintes fatores impedem o aumento ou reduzem a taxa com que a produtividade poderia crescer no nosso país:

1. Educação: apesar de ter mais gente estudando - na última década ocorreu aumento de 2 anos na média do estudo dos trabalhadores -, a qualidade do ensino é um grande problema, pois cerca de $40 \%$ dos universitários brasileiros são considerados analfabetos funcionais. Há falta de alinhamento entre os conhecimentos transmitidos e o que as empresas precisam para produzir mais (os economistas definem isto como "brecha de habilidades");

2. Tecnologia e Inovação: a produtividade não depende apenas da capacidade e empenho dos trabalhadores. Um país pode adquirir ou produzir tecnologia. No Brasil, ambos os casos enfrentam dificuldades;

3. Burocracia e Infraestrutura: obriga as empresas a terem elevado número de pessoas que não trabalham na sua atividade-fim;

4. Competição Externa: o "economista liberal" entende que as empresas não devem ser protegidas, enquanto o "economista desenvolvimentista" acha que o governo deve protegê-las até que elas consigam aguentar a competição externa. Porém, como afirma Marcelo Moura, do Insper [20]: "Temos uma indústria automobilística que diz precisar de ajuda há 50 anos - alguma hora isso tem de acabar".

Adicionalmente, o fato da nossa produção por habitante ser muito menor que a dos países desenvolvidos pode decorrer de uma combinação de dois conjuntos de motivos, ou seja: (a) temos menos recursos, menos máquinas com tecnologia avançada e pessoal menos qualificado; (b) fazemos pior uso dos recursos que temos, i. e., somos menos eficientes.

Então, são altamente discutíveis as argumentações sobre produtividade, se elas não considerarem diversos outros aspectos das sociedades humanas e do nosso planeta.

Por sua vez, assunto intimamente ligado à produtividade é a "competitividade" e uma das principais dificuldades reside exatamente em como definir e medir este fator, pois os dois principais níveis de referência, a "firma" e a "nação", em geral têm diferentes objetivos. Enquanto para uma nação o objetivo é (ou sempre deveria ser) manter e melhorar o padrão de vida dos seus cidadãos, para uma firma a (principal) meta é lidar com sucesso com a competição internacional, tendo lucro e aumentando sua participação no mercado. Assim sendo, o problema do emprego, por exemplo, deve ser matéria prioritária para um país (ou sempre teria que ser), mas necessariamente não é objetivo essencial de uma firma.

Nessa cadeia de fatore interligados, aparece subsequentemente a "inovação". De há muito foi percebido que não serão as universidades que realizarão as inovações nos volumes e velocidades necessárias, mesmo num pais com as características do Brasil. Isto fundamentalmente se deve ao fato de que as principais funções das universidades são formar recursos humanos e desenvolver ideias, as quais um dia poderão, ou não serem aplicadas. Além disto, é discutível se as universidades conseguem desenvolver tecnologia com a agilidade e o sigilo requerido pelas empresas, pois na maioria das vezes elas não sabem comercializar os possíveis produtos gerados. Há quase duas décadas chamávamos a atenção [21] para as diferenças brutais entre o Brasil e a Coréia do Sul, com relação aos números de cientistas e engenheiros trabalhando em universidades, empresas e institutos de pesquisa. Naquela época na Coréia do Sul existiam quase 10 vezes mais destes profissionais trabalhando em empresas do que no Brasil. O efeito do maciço investimento da Coréia do Sul em P\&D e na formação de recursos humanos de alto nível atuando nas empresas foi fundamental para o aumento da riqueza do país. Na Figura 8 [adaptado de 6] está a evolução do PIB per capita desde 1820 do Brasil (era cerca de US\$646 de 1990) e da Coréia do Sul (era cerca de US\$600 de 1990), até 2001, ano que a Coréia do Sul ultrapassou US\$14.000, enquanto o Brasil não alcançou US\$6.000. 
É interessante observarmos, que este enorme aumento do PIB per capita da Coréia do Sul foi acompanhado de crescente automação, conforme podemos ver na Figura 9, o que inclui tanto compras de robôs, quanto aumento da proporção deles em relação aos empregados em manufatura [22]. Notamos que a Coréia do Sul, Japão e Alemanha possuem as mais elevadas proporções de robôs por empregados e que o primeiro país somente se encontra aquém da China em vendas destas máquinas.

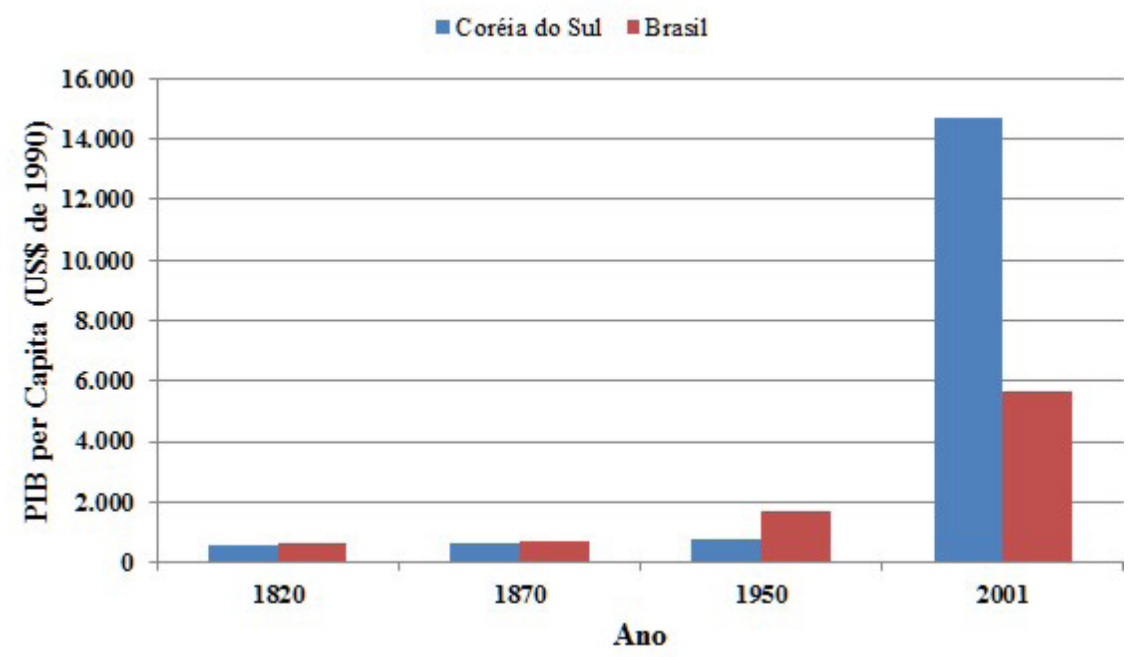

Figura 8. Evolução do PIB per capita da Coréia do Sul e do Brasil desde 1820 [adaptado de 6].

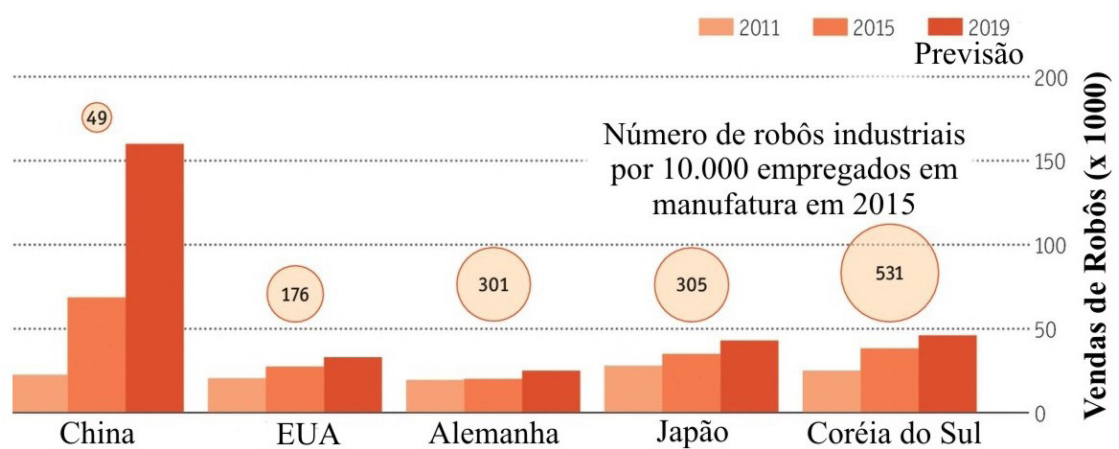

Figura 9. Vendas de robôs e proporção destas máquinas com relação aos empregados em manufatura para diversas importantes economias [22].

Em síntese, os interesses das firmas nem sempre coincidem com aqueles das nações e o grande capital que elas devem esperar receber do país no qual estão sediadas é o humano. Quanto melhor for a qualidade deste capital, maiores serão as vantagens dessas firmas.

\section{Alguns Subsídios Adicionais e Conclusões}

Conforme a OECD [3], devemos analisar as seguintes questões para melhorar a produtividade, a competitividade e a inovação nas firmas:

1.A força das firmas que operam globalmente e nas fronteiras do conhecimento, resulta delas otimizarem os capitais tecnológico, organizacional e humano. Essas firmas têm capacidade e habilidade para inovar os processos de produção através de cadeias de valores globais (CVGs) e se apoiam em meios digitais para rapidamente difundir e replicar ideias. Lembramos que a produção internacional, comércio e investimentos são cada vez mais organizados em CVGs, onde os diferentes estágios dos processos de produção estão localizados em distintos países; 
2. A distância cada vez maior entre estas firmas globais "de ponta" e as restantes, levanta questões sobre os obstáculos que evitam todas as firmas de adotar inovações bem conhecidas e semelhantes. Isto também sugere que o crescimento futuro dependerá largamente de reviver a "máquina de difusão", a qual impulsionou o crescimento da produtividade na maior parte do século XX, mais notavelmente na manufatura. Aumentar a produtividade de firmas "atrasadas" através da difusão, poderia também reduzir o aumento da desigualdade em salários;

3. Difusão da produtividade é especialmente desafiadora no setor de serviços, parcialmente devido a baixas pressões de competitividade que atenua o incentivo para adotar as melhores práticas. $O$ setor de serviços se tornará cada vez mais dispendioso por duas razões, ou seja, o peso deste setor na economia continuará a aumentar e ele pode impedir o efetivo funcionamento das CVGs, pois a globalização depende fundamentalmente de logística, finanças e comunicação.

Por sua vez, o alcance da difusão depende de quatro fatores-chave, i. e. [3]: (i) conexões globais, através de comércio, investimento estrangeiro direto, participação em CVGs e mobilidade internacional de trabalho qualificado; (ii) experimentação pelas firmas, especialmente as iniciantes, com novas ideias, tecnologias e modelos de negócio; (iii) realocação eficiente de recursos escassos para sustentar o crescimento de firmas inovadoras; (iv) investimentos sinérgicos em P\&D, habilidades e "know-how" organizacional, particularmente em capital gerencial - que permite economias absorver, adaptar e colher completamente os benefícios das novas tecnologias.

Então, para reativar o crescimento da produtividade, os legisladores podem fazer o seguinte: (i) manter avançando a fronteira global de inovação, investindo significativamente mais em pesquisa básica para suportar a emergência contínua de inovações; (ii) reviver a "máquina de difusão", para transferir das firmas da fronteira do conhecimento para aquelas atrasadas, além de eficiente alocação de recursos escassos, sendo necessário incentivar as firmas a adotarem melhores tecnologias e práticas de negócios; (iii) colaboração entre universidades e firmas deve ser incentivada, principalmente as firmas pequenas, para que elas se beneficiem das conexões das universidades com o conhecimento global, laboratórios de pesquisa, etc.; (iv) implementar políticas que melhorem a alocação de recursos escassos, tais como trabalho, capital e habilidades.

Promover inovação e estimular a difusão do conhecimento requer um ambiente onde recursos escassos, particularmente talento humano, fluem para seu melhor uso. Reviver a difusão e melhorar alocação de recursos tem o potencial de não somente manter um crescimento acelerado da produtividade, mas também de fazer este crescimento mais inclusivo, por permitir mais firmas e trabalhadores colher os benefícios da economia do conhecimento [3].

As recomendações da OECD que acima transcrevemos são ótimas e o modelo se encaixa quase que perfeitamente para a maioria dos países desenvolvidos. Entretanto, somos da opinião que elas precisam sofrer grandes adaptações para quase todos os países em desenvolvimento, pois neste caso em qualquer discussão que pretenda ser séria e abrangente sobre as questões que envolvam produtividade, competitividade e inovação, devemos reconhecer que:

1. Pode ser de muito difícil solução remover, ou amenizar as sequelas deixadas nos povos que foram brutalmente colonizados, notavelmente aquelas invasões promovidas por certos países europeus na América Latina e África (evidentemente não somente nestes casos). Portanto, numa economia global, posições pedantes e racistas de cidadãos destes países com relação aos habitantes das ex-colônias somente prejudicam a necessária colaboração entre ambos os grupos;

2. Os acidentes geográficos e o clima exercem inegáveis efeitos sobre a formação e o desenvolvimento das sociedades, mas os níveis distintos que elas alcançaram nada têm a ver com diferenças biológicas. Nas terras de mesma latitude (leste-oeste e vice-versa) é muito mais rápida a difusão de culturas, animais domesticados, produtos agrícolas, germes etc., do que nas terras de mesma longitude (norte-sul e vice-versa). Estes fatores também retardam a velocidade da troca de experiências entre os povos e reduzem de maneira geral quão rapidamente eles avançam tecnologicamente. Porém, não estamos afirmando que necessariamente estes povos eram menos felizes do que os invasores portadores de alta tecnologia; 
3. Qualquer nação somente poderá realmente prosperar, quando os seguintes fatores estiverem concomitantemente disponíveis: (i) direitos de propriedade; (ii) racionalismo científico; (iii) existência de mercados de capital; (iv) transporte e comunicações rápidos e eficientes. Evidentemente estes fatores implicam em considerações de ordem política e institucional, com harmonias que simplesmente não existem em muitos países neste estágio de desenvolvimento;

4. Vários países desenvolvidos (principalmente, mas não somente) cometem grandes agressões contra o nosso ambiente e é provável que não seja mais possível impedirmos que alterações climáticas (talvez de dimensões bíblicas) ocorram. Mesmo nações que se diziam "progressistas", sabemos hoje, cometeram (e cometem) horrendos crimes ambientais. Como consequência, num futuro próximo talvez seja necessário desenvolvermos novas tecnologias para simplesmente não sermos extintos da face da Terra. Portanto, todas as instituições de ensino, em todos os níveis, deveriam estar ensinando aos seus alunos meios para gerar tecnologias que operem em harmonia com a Mãe Terra.

\section{Agradecimentos}

Queremos agradecer sinceramente aos diversos autores e instituições, cujos trabalhos utilizamos neste artigo. Em diversos casos transcrevemos literalmente o que escreveram, principalmente para que as futuras gerações conheçam as teorias, as ideias e os fatos que relatam. Apesar de termos citado todas as obras que utilizamos, expressamos desde já nossa gratidão e pedimos compreensão dos autores e instituições, pois nosso único objetivo foi ampliar a difusão do conhecimento e tentar reduzir a dificuldade da raça humana viver sobre a Terra.

\section{Referências}

[1] Coase RH. The nature of the firm. Economica. 1937;4(16):386405. http://dx.doi.org/10.1111/j.1468-0335.1937.tb00002.x.

[2] Krugman P. The age of diminishing expectations. Cambridge: The MIT Press; 1994. cap. 1.

[3] Organization for Economic Cooperation and Development OECD. The future of productivity: preliminary version. Paris: OECD; 2015.

[4] Pirró e Longo W. Tecnologia e soberania nacional. São Paulo: Nobel, PROMOCET; 1984.

[5] Diamond J. Armas, germes e aço. Rio de Janeiro: Record; 2010.

[6] Maddison A. The world economy: historical statistics. Paris: OECD Publishing; 2003. http://dx.doi.org/10.1787/9789264104143-en.

[7] Piketty T. O Capital no século XXI. Rio de Janeiro: Intrínseca; 2014.

[8] Council on Environmental Quality and the Department of State. The global report to the president: entering the twenty-first century. Washington: Government Printing Office; 1980. Vol. 1.

[9] Machado IG. Mundos diferentes. Soldagem \& Inspeção. 1998;4(2):28-29.

[10] Boorstin DJ. Os descobridores. Rio de Janeiro: Civilização Brasileira; 1989.

[11] Bernstein WJ. Uma breve história da riqueza. São Paulo: Fundamento Educacional; 2015.

[12] The Economist. The Economist e Thomson Reuters. The Economist. 2015. Aug 15.
[13] The Economist. International Labour Organisation. The Economist. 2015. Aug.

[14] Subramanian A. Eclipse: living in the shadow of China's economic dominance. Washington: Peterson Institute for International Economics; 2011.

[15] Caselli F. The Latin American efficiency gap, Jul 2014. In: Araujo JT, Vostroknutova E, Wacker KM, Clavijo M. Understanding the income and efficiency gap in Latin America and the Caribbean. Washington: World Bank; 2016.

[16] Castro CM. As profundezas da improdutividade. O Estado de São Paulo. 2015. Março 12.

[17] Rolli C, Fagundes Á. Um trabalhador americano produz como quatro brasileiros. Folha de São Paulo. 2015. Maio 31.

[18] Mena F. Oxfam Brasil ONG britânica no seu relatório “A Distância que nos une: um retrato das desigualdades brasileiras" (lançado no Brasil no dia 25/09/2017). Folha de São Paulo. 2017. Set 26; Seção Mercado.

[19] Perrin F, Portinari N. Desigualdade de renda no Brasil não caiu entre 2001 e 2015, aponta estudo. Folha de São Paulo. 2017 Setembro 8.

[20] Costas R. Entenda por que a produtividade no Brasil não cresce. BBC Brasil em São Paulo. 2014 Maio 27.

[21] Machado IG. Pesquisa \& competitividade \& globalização. Soldagem \& Inspeção. 2000;6(10):16-18.

[22] The Economist. International Federation of Robotics \& The Economist. The Economist. 2017. Nov. 